\title{
A IMPORTÂNCIA DAS BACTÉRIAS LÁTICAS NA SEGURANÇA E QUALIDADE DOS QUEIJOS MINAS ARTESANAIS
}

\section{The role of lactic acid bacteria in the safety and quality of Minas artisanal cheeses}

\author{
Marina Barroso de Antonio ${ }^{{ }^{*}}$, Beatriz Martins Borelli ${ }^{1}$
}

\begin{abstract}
RESUMO
O queijo Minas artesanal é um produto que possui aroma, textura e sabor únicos, além de sua produção fazer parte de toda uma tradição e cultura familiar. O leite cru, matéria prima para fabricação desse queijo, possui naturalmente microrganismos benéficos, conhecidos como bactérias ácido-láticas, responsáveis pelas características organolépticas e segurança microbiológica do queijo, uma vez que produzem diversas substâncias durante sua maturação, inclusive antimicrobianas, que podem ser antagonistas de patógenos. A seguinte revisão apresenta informações sobre a atividade antagonista das bactérias láticas e sua capacidade de garantir a segurança e qualidade do queijo artesanal.
\end{abstract}

Palavras-chave: bacteriocina; maturação; patógeno.

\begin{abstract}
Artisanal Minas cheese is a product that has a unique aroma, texture, and flavor, in addition, its production is part of a family tradition and culture. Raw milk, the raw material used for making this cheese, naturally has benefic microorganisms, known as lactic acid bacteria, responsible for the organoleptic characteristics and microbiological safety of the cheese, since they produce many substances during ripening, including antimicrobials, which can be antagonists of pathogens. The following review presents information on the antagonistic activity of lactic acid bacteria and their ability to guarantee the safety and quality of artisanal cheese.

Keywords: bacteriocin; ripening; pathogen.

1 Pontifícia Universidade Católica de Minas Gerais, Campus Coração Eucarístico, Av. Dom José Gaspar, 500, Coração Eucarístico, 30535-901, Belo Horizonte, MG, Brasil. E-mail: marinabantonio@gmail.com

* Autor para correspondência
\end{abstract}




\section{INTRODUÇÃO}

A produção de queijos artesanais baseiase na tradição e cultura histórica de um povo ou região e são fabricados utilizando técnicas passadas de geração em geração que nem sempre atendem ao padrão sanitário previsto nas legislações ou nas Boas Práticas de Fabricação. Apesar disto, a procura por esses produtos consiste na busca por um alimento de origem conhecida, elaborado de forma artesanal, com utilização de insumos naturais, podendo o consumidor ter contato direto com o produtor, gerando uma relação de confiança, ao contrário do produto industrializado, em que não se conhece o processo de produção (ZUIN; ZUIN, 2008; CRUZ; SCHNEIDER, 2010).

No estado de Minas Gerais, um dos principais produtos tradicionais é o Queijo Minas Artesanal produzido a partir do leite cru, não pasteurizado. Pelo fato desse tipo de queijo ser fabricado com leite não pasteurizado, pode ocorrer a presença ou contaminação por microrganismos patogênicos indesejáveis como coliformes, Staphylococcus aureus, Listeria ssp., Brucella ssp., Salmonella ssp. e outros, podendo causar intoxicações e/ou infecções alimentares e em alguns casos levar à morte (OLIVEIRA, 2014; MELLO et al. 2010).

Porém, entre os surtos de intoxicação alimentar, aqueles causados pela ingestão de queijos artesanais não têm maior prevalência, possivelmente devido a outros fatores de proteção que esses queijos apresentam. Um desses fatores é a presença de bactérias láticas capazes de produzir diversos metabólitos, dentre eles as bacteriocinas, que apresentam efeitos tóxicos contra bactérias patogênicas (HEREDIA-CASTRO et al., 2017; OLIVEIRA, 2014).

O fermento utilizado na fabricação do queijo Minas artesanal é conhecido como pingo, que corresponde ao soro que escorre dos queijos cobertos com sal grosso que foram produzidos no dia anterior, rico em bactérias. Essas bactérias são as bactérias láticas, responsáveis pela fermentação, maturação, sabor e texturas únicos desse queijo. Além disso, essas bactérias são capazes de inibir o crescimento de patógenos no queijo, melhorando a qualidade e segurança microbiológica desse produto (AMORIM, 2013).

Este trabalho de revisão teve como objetivo apresentar informações sobre a atividade antagonista das bactérias láticas sobre possíveis microrganismos patogênicos presentes no queijo Minas artesanal.

\section{REFERENCIAL TEÓRICO}

\section{Os queijos Minas artesanais}

No estado de Minas Gerais, o início da produção queijeira ocorreu no século XVIII, trazida pelos portugueses que já fabricavam o queijo na Serra da Estrela, em Portugal, e a partir de então essa cultura se firmou, principalmente neste estado, tornando-se uma herança que foi passada de geração em geração. Atualmente o modo artesanal de fazer o Queijo Minas é reconhecido como Patrimônio Cultural Imaterial Brasileiro pelo IPHAN (BRASIL, 2008; RAFAEL, 2017). Hoje existem sete regiões reconhecidas como produtoras tradicionais do queijo Minas artesanal: Araxá, Campos das Vertentes, Canastra, Cerrado, Serra do Salitre, Serro e Triângulo Mineiro (EMATER, 2019).

O queijo Minas artesanal é um produto elaborado a partir do leite cru, conforme a tradição histórica e cultural de cada região, não apresentando uma padronização, por ser produzido em diferentes locais com diferentes processos de produção, possuindo uma diversidade de sabores e texturas de acordo com o ambiente, o clima, o tipo de pastagem e o fermento utilizado (OLIVEIRA, 2014; LIMA; LEAL, 2017; RAFAEL, 2017). 
É comum a todos os processos de fabricação do queijo Minas artesanal o uso do fermento endógeno, ou pingo. Todo o processo fermentativo é conduzido pela microbiota presente no leite e no ambiente, sendo representada, em sua maior parte, por bactérias ácido-láticas (RAFAEL, 2017; AMORIM, 2013). A microbiota presente em cada produto depende das características do ambiente e do tipo de nutrição dos animais, variando de acordo com o local da produção. Por isto cada queijo apresenta suas próprias peculiaridades, apresentando grande variabilidade entre cada tipo (OLIVEIRA, 2014).

A maturação dos queijos é de suma importância para garantir a qualidade do produto. Depende de diversos fatores, como temperatura e $\mathrm{pH}$ adequados para o desenvolvimento das bactérias ácidoláticas, possibilitando obter as características sensoriais desejadas e a segurança microbiológica do produto final (RESENDE, 2014; RAFAEL, 2017; PEHRSON, 2017).

Durante a maturação ocorre o processo de fermentação do açúcar do leite, com a produção de uma grande quantidade de enzimas proteolíticas, glicolíticas e lipolíticas, responsáveis pelo desenvolvimento da textura e flavor dos queijos, e, são produzidos, também, ácido lático e outras substâncias antimicrobianas, como as bacteriocinas, controlando e inibindo o crescimento da microbiota patogênica indesejável (RAFAEL, 2017).

Devido a esta variedade de processos de fabricação e por se utilizar o leite cru, sem o tratamento térmico pela pasteurização, o queijo artesanal encontra diversos entraves em sua regulamentação. A primeira regulamentação sobre os queijos artesanais foi a Resolução $\mathrm{n}^{\mathrm{o}}$ 7, de 2000, do Ministério da Agricultura, Pecuária e Abastecimento (MAPA), que estabelecia um período de maturação de 60 dias paras os queijos fabricados com leite cru, período esse considerado muito longo, podendo comprometer as características sensoriais do queijo artesanal (BRASIL, 2000; DINIZ, 2013; RAFAEL, 2017).

Após diversos estudos, foi publicado o Decreto $\mathrm{n}^{\circ} 44.864$, de $1^{\circ}$ de agosto de 2008 , permitindo a comercialização, apenas dentro do estado de Minas Gerais, de queijos com menos de 60 dias de maturação, desde que sua segurança fosse comprovada. Porém, como forma de esclarecer diversas questões, esse Decreto foi reformulado através da publicação da Instrução Normativa $n^{\circ} 57$, de 2011, pelo MAPA, permitindo a comercialização em outros estados brasileiros, sendo atualizada (revogada) pela Instrução Normativa $n^{\circ} 30$ de 07 de agosto de 2013 (MINAS GERAIS, 2008; RAFAEL, 2017; BRASIL, 2011; BRASIL, 2013; DINIZ, 2013).

Em 2012 foi publicada, em Minas Gerais, a Lei $n^{\circ} 20.549$, que estabelece como obrigação do estado a fiscalização de todo processo produtivo do queijo Minas artesanal, além de reconhecer outras novas variedades de queijos artesanais (MINAS GERAIS, 2012; DINIZ, 2013).

O período de maturação do queijo Minas artesanal, feito com leite cru, foi determinado através da Portaria $n^{\circ} 1305$ do IMA (Instituto Mineiro de Agropecuária), definindo um período de 17 dias de maturação para o queijo do Serro e 22 dias para Canastra, Araxá, Cerrado e Campo das Vertentes (MINAS GERAIS, 2013).

Por fim, em 18 de dezembro de 2018, entrou em vigor a Lei $\mathrm{n}^{\circ} 23.157$, revogando a lei de 2012, e, juntamente com a Lei Federal $n^{\circ} 13.680 / 2018$, oficializa a produção artesanal de queijo, reconhecendo diferentes variedades e tipos de queijos, que deverão ser identificados, em todo território nacional, pelo selo ARTE, sendo inspecionado e fiscalizado, prioritariamente, de maneira orientadora, a fim de capacitar os produtores (MINAS GERAIS, 2018; BRASIL, 2018). 


\section{Segurança microbiológica}

Afirmar que um alimento é seguro significa dizer que ele não oferece risco à saúde do consumidor, ou seja, é um produto fabricado com os cuidados higiênicossanitários necessários, livre de qualquer perigo físico, químico ou biológico (RESENDE, 2014).

As intoxicações e infecções alimentares, também conhecidas como Doenças Transmitidas por Alimentos, provocadas por microrganismos patogênicos, têm aumentado e são consideradas uma importante causa de morte, já que a contaminação alimentar é bastante comum devido a presença de microrganismos no ambiente, nos animais, plantas e no próprio homem (AMORIM, 2013).

Uma das principais causas de contaminação de alimentos é a manipulação inadequada, tanto da matéria-prima quanto dos utensílios de trabalho, devido a uma higienização deficiente dos equipamentos e pessoal, como higienização incorreta das mãos, conversar ou tossir durante o preparo dos alimentos, e a não utilização de Equipamentos de Proteção Individual (EPI), como toucas, aventais, máscaras e luvas (SILVA, 2015).

O leite, utilizado na produção do queijo, se encontra estéril dentro do úbere de um animal saudável. Entretanto, durante o processo da ordenha, o leite passa a ter contato com o meio externo e todos os possíveis microrganismos, sendo necessária uma correta higienização do manipulador, do úbere e dos utensílios utilizados, a fim de minimizar a contaminação do leite. Além disso, o processo de pasteurização, que consiste no tratamento térmico do leite, pode eliminar os microrganismos patogênicos (DINIZ, 2013).

Os queijos artesanais, por serem fabricados utilizando leite cru e técnicas tradicionais de origem familiar e cultural, sem o uso de procedimentos tecnológicos, como a pasteurização, podem conter patógenos. Porém, mesmo os queijos fabricados com leite pasteurizado podem sofrer contaminação, caso ocorra falhas durante sua manipulação devido à higienização deficiente (CARVALHO, 2015; DINIZ, 2013).

Para que os queijos artesanais sejam considerados seguros é necessário que o leite seja proveniente de um rebanho sadio, que a água destinada à produção do queijo seja de qualidade e o processamento e estocagem sejam feitos de maneira higiênica, a fim de manter parâmetros microbiológicos recomendados (RESENDE, 2014; DINIZ, 2013).

Um leite de qualidade não deve conter bactérias patogênicas, nem corpos estranhos ou produtos químicos como antibióticos, indicando que as vacas eram sadias e o rebanho não apresenta nenhuma doença infectocontagiosa. Além disso, a água utilizada durante todo processamento do leite até o queijo deve estar dentro dos padrões físicos, químicos e microbiológicos, evitando a contaminação do produto por microrganismos indesejáveis veiculados pela água (CARVALHO, 2015).

Existem alguns padrões microbiológicos, exigidos pela Resolução RDC nº12/2001 (BRASIL, 2001), baseados na contagem máxima aceitável de microrganismos presentes no queijo, para que o Queijo Minas Artesanal apresente segurança alimentar e seja aceito no mercado consumidor. Os parâmetros microbiológicos avaliados são: presença de coliformes a $30{ }^{\circ} \mathrm{C}$ e $45^{\circ} \mathrm{C}$, Staphylococcus coagulase positiva, Listeria sp. e Salmonella sp., sendo que apenas a presença de Listeria ou Salmonella, independente da contagem, é inaceitável (BRASIL, 2001; RESENDE, 2014).

Os coliformes totais ou a $30{ }^{\circ} \mathrm{C}$ são bactérias Gram negativas, em forma de bacilos, encontradas nas fezes, no meio 
ambiente e no solo. Fazem parte desse grupo os gêneros Enterobacter, Escherichia, Citrobacter e Klebsiella. Apenas a Escherichia coli é colonizadora primária do trato intestinal de animais e do homem. São utilizados como indicadores higiênico-sanitários e sua presença nos queijos ou em outros alimentos indica que houve deficiência nos processos de limpeza, produção e estocagem, com contaminação durante ou após o processamento (DINIZ, 2013; CARVALHO, 2015; RESENDE, 2014).

Já os coliformes termotolerantes ou a $45{ }^{\circ} \mathrm{C}$, quando presentes, indicam que possivelmente houve contato do alimento com material de origem fecal e o principal indicador dessa contaminação é a $E$. coli, presente em aproximadamente $90 \%$ dos casos. Essa bactéria é patogênica e causadora de gastroenterites agudas e hemorrágicas (CARVALHO, 2015; AMORIM, 2013)

O gênero Staphylococcus inclui diversas espécies de bactérias, sendo a mais importante a Staphylococcus aureus coagulase positiva, pois é a principal responsável por intoxicações alimentares devido à produção de toxinas, que, mesmo após a destruição da bactéria, pelo tratamento térmico, permanecem ativas nos alimentos (RESENDE, 2014; AMORIM, 2013). A presença de S.aureus nos queijos ou outros alimentos está relacionada à manipulação indevida, já que esse microrganismo pode ser encontrado em humanos e animais, colonizando a pele, as narinas e outras cavidades externas do corpo. Pode estar associada também a casos de mastite bovina (DINIZ, 2013; RESENDE, 2014).

A Salmonella sp. é um importante patógeno gastrointestinal, responsável por graves intoxicações alimentares. Encontrase amplamente distribuída no ambiente e pode sobreviver em alimentos por um longo período de tempo, sendo considerada um grave problema de saúde pública. Devido a isto, foi estabelecido pela legislação brasileira a sua ausência em 25 gramas de amostra de qualquer alimento (DINIZ, 2013; AMORIM, 2013).

Fazem parte do gênero Listeria seis espécies principais, a L.monocytogenes, L.ivanovii, L.seeligeri, L.innocua, L.welshimeri e L.grayi, sendo a L.monocytogenes considerada a mais patogênica e de alta letalidade. É encontrada principalmente no solo e em vegetais, podendo facilmente contaminar alimentos in natura, como o leite cru e o queijo artesanal, e representando uma importante parcela dos casos de infecção alimentar. Por isto, assim como a Salmonella, deve estar ausente em 25 gramas de amostra alimentar (AMORIM, 2013; RESENDE, 2014).

\section{As bactérias ácido-láticas}

As bactérias ácido-láticas (BAL) são Gram-positivas, catalase negativa, não patogênicas, sendo os principais microrganismos cultiváveis, presentes no leite cru, representando $20 \%$ a $30 \%$ das espécies (PEHRSON, 2017; RAFAEL, 2017). Os gêneros, na maior parte do leite bovino, são Lactococcus, Enterococcus, Streptococcus, Lactobacillus, Leuconostoc e Pediococcus (PEHRSON, 2017).

As BAL são responsáveis pela fermentação do leite e podem ser divididas em dois grupos distintos, as homofermentadoras, que produzem, principalmente, ácido lático, ao fermentar a glicose, e as heterofermentadoras, que geram outros produtos como lactato, dióxido de carbono, ácido acético, diacetil e etanol (OLIVEIRA, 2014; BRUNO; CARVALHO, 2009).

A microbiota fermentadora é formada, inicialmente, por bactérias do gênero Lactococcus, acidificadoras, convertendo rapidamente a lactose em ácido lático. Por crescerem em $\mathrm{pH}$ entre 6,0 e 6,5 e serem sensíveis ao sal, sua presença é reduzida durante o processo de maturação, à medida 
que o $\mathrm{pH}$ diminui e a concentração do sal aumenta (BRUNO; CARVALHO, 2009; OLIVEIRA, 2014).

Com o avançar do tempo de maturação, as bactérias dominantes passam a ser do gênero Lactobacillus, mais resistentes ao sal e tolerantes ao meio ácido (OLIVEIRA, 2014). Essas são divididas em três grupos, de acordo com o produto final da fermentação. O primeiro grupo é formado por bactérias homofermentadoras, como L. delbrueckii subespécies lactis e bulgaricus, e L. helveticus. O segundo grupo inclui bactérias heterofermentadoras facultativas, como L. casei, L. paracasei e $L$. plantarum. No terceiro grupo encontram-se bactérias heterofermentadoras obrigatórias, responsáveis por produzir gás e sabores indesejáveis no queijo, durante a cura, porém, esses lactobacilos ocorrem em menor frequência (BRUNO; CARVALHO, 2009).

O gênero Streptococcus possui apenas uma espécie fermentadora, a S.thermophilus, muito utilizada na fermentação de queijos de massa cozida, devido sua resistência ao aquecimento e por suportar uma alta concentração de $\mathrm{NaCl}$. Fermenta rapidamente a lactose em ácido lático e seu uso pode ser combinado com Lactobacillus, capaz de fermentar também a galactose, que não é utilizada pelo S.thermophilus (ANDRADE, 2009; BRUNO; CARVALHO, 2009).

As bactérias ácido-láticas dos gêneros Enterococcus e Leuconostoc são responsáveis, principalmente, pelas características organolépticas dos queijos, utilizando o citrato para produção de compostos aromáticos voláteis. Fazem parte da microbiota secundária e, por crescem em uma ampla faixa de temperatura, são encontradas tanto nos queijos de leite cru como nos de massa cozida (BRUNO; CARVALHO, 2009; ANDRADE, 2009).

Os Enterococcus, apesar de fazerem parte da microbiota lática no queijo, produzindo compostos aromáticos e enterocinas capazes de inibir diversos patógenos, sua presença nos alimentos é bastante contestada, já que são bactérias que estão presentes no trato gastrointestinal de mamíferos, podendo agir como um patógeno oportunista, podendo indicar condição de higiene inadequada e possível contaminação fecal dos alimentos (RESENDE et al., 2011; LUIZ et al., 2016; BRUNO; CARVALHO, 2009; LIMA et al. 2009).

O ácido lático produzido pelas BAL, durante a fermentação, acelera o processo de coagulação do leite e contribui para o desenvolvimento das características sensoriais do queijo, como o sabor, aroma e textura. Porém, uma das principais funções do ácido e de outros metabólitos produzidos com a fermentação é a atividade antimicrobiana e a conservação dos alimentos (RAFAEL, 2017; ANDRADE, 2009).

\section{Compostos antagônicos produzidos pelas BAL}

Atualmente a atividade antimicrobiana das BAL tem sido bastante estudada. Essa ação é devido à produção de ácidos orgânicos e bacteriocinas, que antagonizam e inibem o crescimento de microrganismos competidores e patogênicos, sendo utilizadas como bioconservadoras dos alimentos (OLIVEIRA, 2014; RAFAEL, 2017).

As bacteriocinas são peptídeos antimicrobianos sintetizados no ribossomo e secretados no meio extracelular, apresentando resíduos de vários aminoácidos, o que lhes confere caráter catiônico, hidrofóbico e anfipático, além de possuir ação bactericida ou bacteriostática, atuando, preferencialmente, contra bactérias Gram positivas (HEREDIACASTRO et al., 2017; COSTA, 2016; ANDRADE, 2009).

A classificação das bacteriocinas é feita de acordo com suas características bioquímicas e estrutura, sendo dividida em 
cinco classes. A classe I são os lantabióticos, formada por peptídeos de baixo peso molecular, resistentes a altas temperaturas e mudanças de $\mathrm{pH}$, e possuem aminoácidos modificados na sua estrutura, como lantionina e $\beta$-lantionina. A nisina, que é a única bacteriocina atualmente aprovada pelo FDA (Food and Drug Administration), como sendo segura para uso em alimentos (Generally Reconized as Safe-GRAS), faz parte dessa classe (COSTA, 2016; HEREDIA-CASTRO et al., 2017).

A classe II, ou não lantabióticos, é formada por pequenos peptídeos, sem aminoácidos modificados, e resistentes ao calor. É subdividida em cinco subclasses, IIa, IIb, IIc, IId e IIe. Na subclasse IIa encontram-se bacteriocinas com alta capacidade de inibição de Listeria sp., como a enterocina, produzida pelos enterococos, e a pediocina, produzida por Pediococcus ssp., que possui também efeito antagonístico sobre $S$. aureus e Clostridium perfringens (ANDRADE, 2009; HEREDIACASTRO et al., 2017, COSTA, 2016).

A pediocina é mais efetiva do que a nisina na inibição de patógenos como $S$. aureus, L. monocytogenes, e Gram negativos como Pseudomonas e E. coli. Além disso, é estável um uma ampla faixa de $\mathrm{pH}$ e resiste ao aquecimento ou congelamento (SILVA et al., 2018a).

Os peptídeos de alto peso molecular fazem parte da classe III. Já a classe IV é composta por grandes peptídeos, de estrutura complexa, associados a carboidratos ou lipídios. E, por último, a classe $\mathrm{V}$, formada por peptídeos de estrutura circular (HEREDIACASTRO et al., 2017).

A maioria das bacteriocinas atua na membrana citoplasmática dos microrganismos, levando à formação de poros. Essa ação se inicia através da atração eletrostática das bactérias, que possuem fosfolipídios de membrana carregados negativamente, com as bacteriocinas, carregadas positivamente, possibilitando sua ligação. Assim, após a ligação, as bacteriocinas conseguem penetrar na membrana alvo, formando poros ou canais iônicos, permitindo a despolarização com extravasamento de íons de potássio, aminoácidos e componentes de baixo peso molecular, levando à diminuição do gradiente eletroquímico e da síntese de proteínas, DNA e RNA, causando a morte da bactéria (COSTA, 2016; HEREDIA-CASTRO et al., 2017; ANDRADE, 2009).

A utilização das bacteriocinas como bioconservantes apresenta diversas vantagens, como redução das intoxicações alimentares, aumento da vida útil dos produtos e redução de gastos com conservantes. Além disso, não são tóxicas, são biodegradáveis, digestíveis e seguras (ANDRADE, 2009; HEREDIACASTRO et al., 2017).

A nisina foi a primeira bacteriocina a ser comercializada, tendo seus efeitos antimicrobianos demonstrados através da capacidade de inibir o crescimento de $S$. aureus no queijo Minas frescal, sem alterar suas características sensoriais e físicoquímicas (HEREDIA-CASTRO et al., 2017).

Como as bacteriocinas são termoestáveis e suportam variações de $\mathrm{pH}$, seu uso é viável no processamento de queijos, podendo ser introduzidas através da adição de BAL, que já estão presentes no queijo artesanal, por serem feitos com o leite cru. É possível, também, purificar o antimicrobiano, como, por exemplo, a nisina, e aplicá-lo diretamente no alimento (ANDRADE, 2009; COSTA, 2016). Outra maneira é a aplicação da bacteriocina parcialmente purificada e ligada a um transportador, que permite a liberação contínua de acordo com o gradiente do meio (COSTA, 2016).

As BAL, por serem consideradas microrganismos GRAS, podem ser utilizadas com segurança para produção e conservação de alimentos. Com isto, apesar de apenas a nisina ser aprovada pelo FDA, outras 
bacteriocinas têm sido isoladas para serem aplicadas com o mesmo fim (COSTA, 2016, ANDRADE, 2009).

Além das bacteriocinas, as BAL produzem também outras substâncias antimicrobianas, como o diacetil e o peróxido de hidrogênio. O diacetil é produzido a partir da fermentação do citrato. Age bloqueando o sítio de ligação da enzima responsável pela utilização da arginina, inibindo a síntese de proteínas essenciais. É considerado um antimicrobiano de amplo espectro (GUEDES NETO, 2008; RAFAEL, 2017). O peróxido de hidrogênio, produzido na presença de oxigênio, atua como oxidante, desnaturando enzimas de membrana das bactérias, aumentando assim sua permeabilidade. Além disso, na presença de leite cru, que é o usado na produção dos queijos artesanais, o peróxido de hidrogênio oxida o tiocianato, componente natural do leite, gerando diversos compostos antimicrobianos (JERONYMO, 2013; CÂMARA, 2012; RAFAEL, 2017).

\section{Atividade antagonista}

As bactérias ácido-láticas com maior potencial de inibição de patógenos presentes nos queijos Minas artesanais, de acordo com estudos realizados por Cunha (2018), Oliveira (2012), Rafael (2017) e Andrade et al. (2014), são as do gênero Lactobacillus. Também foi demonstrada atividade antagonista de bacilos em queijo coalho artesanal (GUEDES NETO et al., 2005) e queijo Minas frescal (GERIA et al., 2014).

Campagnollo et al. (2018) e Seixas (2014) constataram a ação de Enterococcus contra bactérias patogênicas, como Listeria e Salmonella. No artigo de Seixas (2014), Enterococcus foi o principal antagonista da Salmonella. Resultados semelhantes foram encontrados em outras pesquisas, como a de Dias (2014), em queijo coalho, que verificou maior inibição de $E$. coli e $S$. aureus por
Enterecoccus, e Giazzi (2017), que mostrou também a inibição de Listeria innocua e $L$. monocytogenes no queijo Minas frescal.

Devido ao fato das bacteriocinas apresentarem melhor espectro de ação contra bactérias Gram positivas, patógenos como Salmonella typhimurium e Escherichia coli são mais resistentes a ação antimicrobiana (CUNHA, 2018; BRUMANO, 2016; SEIXAS, 2014; ANDRADE et al., 2014; ALEXANDRE et al., 2002). Segundo Rafael (2017), a variada composição de ácidos graxos e a menor concentração de fosfolipídios na membrana celular das bactérias Gram negativas dificulta a formação de poros e a ação das bacteriocinas. Porém, a inibição de bactérias Gram negativas pode ser explicada, de acordo com BordignonJunior et al. (2012), pela concentração de bacteriocinas presentes ou a presença de ácidos capazes de alterar a estabilidade da membrana das bactérias. Outros fatores também podem ser responsáveis, como o diacetil e o peróxido de hidrogênio (GUEDES NETO, 2008; RAFAEL, 2017).

As BAL são capazes de inibir um dos principais agentes de intoxicações alimentares, o $S$. aureus, e também um dos mais letais, a Listeria, ambos frequentemente encontrados em produtos in natura e bastante manipulados, como os queijos artesanais (RESENDE, 2014; ANDRADE et al., 2014).

$\mathrm{O}$ antagonismo entre as BAL pode ocorrer, porém em menor proporção quando comparada à inibição dos patógenos, como foi avaliado nos estudos de Cunha (2018), Andrade et al. (2014), Costa et al. (2013) e Alexandre et al. (2002). Isto foi demonstrado também na pesquisa de Guedes Neto et al. (2005), evidenciando que as BAL não competem entre si e sim atuam de maneira conjunta, contribuindo com o antagonismo sobre os microrganismos patogênicos.

Campagnollo et al. (2018) coletaram amostras de queijos Minas artesanais de várias regiões, produzidos com leite 
cru e pasteurizado inoculados com $L$. monocytogenes e BAL selecionadas, para posterior análise. Nesse estudo foi observado um maior crescimento de L. monocytogenes nos queijos feitos com leite pasteurizado do que nos de leite cru, e a inativação da Listeria foi mais efetiva nos queijos de leite cru do que nos pasteurizados. Além disso, o tempo de maturação necessário para reduzir a concentração de Listeria foi de 15 dias no queijo de leite cru e 22 no pasteurizado. Devido ao fato de a pasteurização eliminar grande parte da microbiota presente no leite, inclusive as BAL, o crescimento de patógenos, quando presentes, é maior, já que houve diminuição na competição entre as bactérias e aumento da disponibilidade de nutrientes.

Conclusão similar foi obtida por Chioda et al. (2006), que analisaram queijo frescal, elaborado com leite pasteurizado, inoculado com L. monocytogenes, com ou sem a inoculação de cultura lática ou BAL. No queijo feito sem a utilização de cultura lática ou BAL ocorreu maior crescimento de Listeria, já que a microbiota presente no queijo não foi suficiente para controlar o crescimento do patógeno, por estar reduzida devido à pasteurização.

\section{Resistência de bactérias patogênicas ao processo de maturação dos queijos}

A maturação dos queijos é muito importante para o desenvolvimento dos microrganismos desejáveis. Durante esse processo ocorrem variações na temperatura, concentração de sal, umidade, $\mathrm{pH}$ e atividade de água, favorecendo o crescimento da microbiota endógena e sua atividade antagonista frente a bactérias patogênicas (RAFAEL, 2017; DORES; FERREIRA, 2012; PAGTHINATHAN; NAFEES, 2015).

Porém, para que a maturação seja eficiente na segurança microbiológica, são necessárias condições satisfatórias de higiene antes, durante e após a fabricação do queijo, evitando uma alta contaminação inicial ou uma recontaminação do produto através de treinamentos e Boas Práticas de Fabricação (BPF) (TEODORO et al., 2013a; FERREIRA et al., 2011; PINTO et al., 2009a). A qualidade da água e do leite utilizados, o controle de pragas e vetores, a limpeza de utensílios e superfícies, a higienização correta das mãos, unhas cortadas e barbas aparadas, o uso de uniformes, e o correto armazenamento e transporte dos produtos são práticas importantes para o controle de qualidade, prevenindo a disseminação de patógenos (MALAGUETA JÚNIOR et al., 2012; MACHADO et al., 2009; MELLO et al., 2010; FERREIRA et al., 2013).

O manejo inadequado durante a ordenha, sem a sanitização dos equipamentos e dos tetos, a não observação de alterações no leite e sinais de inflamação no úbere, pode levar ao aumento da contagem de microrganismos presentes no leite (TEODORO et al.,2013b). Um leite com alta contagem de células somáticas indica presença de mastite nos animais e contaminação por Staphylococcus e outras bactérias patogênicas (SOBRAL et al., 2017).

A legislação brasileira permite a comercialização de queijos feitos a partir de leite cru, com menos de 60 dias de maturação, desde que atendam a requisitos mínimos de qualidade, porém, ainda são encontrados produtos comercializados fora do padrão aceitável (BRASIL, 2011).

Uns dos parâmetros utilizados para avaliar o tempo mínimo de maturação dos queijos é a umidade, sendo o limite máximo de 45,9\% (MINAS GERAIS, 2008). Estudos realizados por Fernandes et al. (2011) e Silva et al. (2012) mostraram que a maioria dos queijos analisados apresentavam umidade acima do permitido. O alto teor de água nos queijos torna-os susceptíveis ao crescimento 
de microrganismos patogênicos (REZENDE et al., 2010).

Rezende et al. (2010) avaliaram amostras de queijo Minas artesanal, frescos e curados, e constatou que $100 \%$ das amostras avaliadas apresentavam contagem de Staphylococcus coagulase positiva (SCP) acima do permitido e mais de $50 \%$ dos queijos, de alta e média umidade, contagem de coliformes fora dos padrões. Resultado semelhante foi demonstrado por Pinto et al. (2016), ao examinar amostras de queijo Minas de Montes Claros e do Serro, encontrando em todas elas resultados de $S$. aureus acima do tolerado e apenas um dos queijos de Montes Claros apresentou-se dentro dos valores máximos para E. coli. No estudo de Andretta et al. (2019), 75,5\% das amostras avaliadas de queijo artesanal do Serro apresentava SCP além dos valores permitidos.

Lima et al. (2011) realizaram uma pesquisa a fim de avaliar os parâmetros microbiológicos dos queijos da Serra do Salitre, antes e depois da implementação de um Programa de BPF, e constatou que após uma melhora na qualidade higiênico-sanitária durante a produção, a contaminação dos queijos por coliformes e $S$. aureus reduziu consideravelmente, com apenas uma amostra, dentre as avaliadas, acima do padrão. O contrário foi observado no estudo de Soares et al. (2018), no qual foi verificado que apenas o treinamento não foi o suficiente para melhorar a qualidade final dos queijos, e a contagem de SCP permaneceu acima do limite.

A resistência de patógenos durante o período de maturação foi avaliada em diversas pesquisas. Borelli et al. (2010) demonstraram que somente após 60 dias de maturação amostras do queijo Minas da Canastra apresentaram contagens de SCP dentro do padrão permitido. $\mathrm{O}$ mesmo foi encontrado por Chesca et al. (2015), em amostras de queijo Minas curado, e por Cardoso et al. (2013) em amostras de queijo Minas do Serro.
Porém, no estudo de Martins et al. (2015), o queijo Minas do Serro se encontrava dentro dos parâmetros e apto ao consumo após 17 dias de maturação, em temperatura ambiente.

A resistência do $S$. aureus durante a maturação do queijo pode ser explicada devido a presença de mastite nas vacas, condições higiênico-sanitárias deficientes durante a manipulação da matéria-prima, contaminação excessiva do leite, das mãos e utensílios utilizados na fabricação, além de variações nos valores de $\mathrm{pH}$ (BORELLI et al., 2011; ROLA et al., 2013; VASEK et al., 2013; ECKERT; WEBBER, 2016; ARMACHUK et al., 2019). Queijos com pH mais baixo propiciam o crescimento das BAL, que toleram meios mais ácidos, e inibem o desenvolvimento de Staphylococcus e outros patógenos (MILANI et al., 2014).

Pesquisas realizadas sobre queijo Minas artesanal de diversas regiões, como Serro, Araxá e Montes Claros, mostraram a presença de Salmonella spp. em queijos maturados até 15 dias, na temperatura ambiente, e 22 refrigerados (MARTINS et al., 2015; PINTO et al., 2016). A contaminação inicial dos produtos ocorreu possivelmente devido condições precárias de higiene na manipulação e armazenamento dos queijos, aumentando a contagem inicial de Salmonella (ALEMDAR; AGAOGLU, 2010; PINTO et al., 2016).

O período mínimo de maturação de cada queijo varia quando é maturado à temperatura ambiente ou sob refrigeração, sendo maior quando refrigerado, pois a temperatura diminui o teor de umidade dos queijos, aumentando a concentração de sal e reduzindo a atividade de água, reduzindo a multiplicação de microrganismos indesejáveis (DORES et al., 2013; MARTINS et al., 2015).

Mata et al. (2016) analisaram a sobrevivência de Listeria innocua ao longo do período de maturação em queijo Minas artesanal e constatou que após 60 dias 
ainda era possível detectar a presença, em menor quantidade, de Listeria no queijo. Em amostras de queijo Minas do Serro, avaliadas por Pinto et al. (2009b), também foi obtido o mesmo resultado. A Listeria é capaz de resistir a diversas condições adversas, como $\mathrm{pH}$, temperatura e atividade de água, porém, por serem menos competitivas, tendem a diminuir ao longo do tempo, evidenciando a importância de um período de maturação adequado (PEREIRA et al., 2009; MELO et al., 2013). Além disso, é possível que o leite utilizado na fabricação dos queijos seja proveniente de animais portadores desse microrganismo (PEREIRA et al., 2009).

Silva et al. (2018b) avaliaram amostras de queijo Minas do Serro, quanto à presença de Brucella ssp., e constatou que 30,9\% delas deram positivo. Na pesquisa de Miyashiro et al. (2007), 15,68\% dos queijos Minas artesanais curados apresentavam Brucella. No estudo de Santiago-Rodriguez et al. (2015), Brucella abortus foi capaz de sobreviver por mais de 17 dias durante a maturação a $24^{\circ} \mathrm{C}$. A Brucella é de grande importância na saúde pública, sendo considerada como uma das principais zoonoses transmitidas através do consumo de produtos lácteos crus, como o queijo artesanal (SANTIAGORODRIGUEZ et al., 2015). O período de maturação estipulado para alguns queijos produzidos em Minas é menor do que o tempo de sobrevivência da Brucella ssp., uma vez que os padrões microbiológicos avaliados não incluem esse patógeno (SILVA et al., 2018b).

No trabalho de Moriconi et al. (2018) foi constatada a presença de Mycobacterium spp. em $12 \%$ das amostras de queijo Minas meia cura. Resultado semelhante foi encontrado por Cezar et al. (2016), que analisaram queijo coalho artesanal encontrando 2,8\% das amostras positivas para Mycobacterium bovis. A M. bovis causa tuberculose e é uma zoonose transmitida principalmente pelo leite contaminado, apesar de existir poucos estudos sobre sua presença nos queijos de leite cru (STARIKOFF et al., 2016; MORICONI et al., 2018). Segundo Starikoff et al. (2016), M. bovis foi detectada em queijos curados com mais de 63 dias de cura, por ser capaz de tolerar ambientes ácidos.

As bacteriocinas produzidas pelas BAL durante a maturação podem ter sua atividade reduzida quando a contaminação inicial é muito alta, propiciando a proliferação de microrganismos indesejáveis. Mutações em bactérias resistentes podem levar a alterações na composição dos fosfolipídios, na espessura e na carga da membrana citoplasmática, afetando a ligação das bacteriocinas e dificultando a formação de poros, inibindo sua atividade antimicrobiana (NISHIE et al., 2012; BALCIUNAS et al., 2013).

É possível perceber que existem diversas falhas na avaliação do tempo mínimo necessário de maturação para que o queijo seja considerado seguro. Algumas bactérias patogênicas não estão incluídas nos parâmetros microbiológicos aceitáveis. Além disso, índices físicos e químicos como a temperatura da maturação, valores de $\mathrm{pH}$ e atividade de água também não foram estabelecidos, considerando que diversos patógenos resistem a uma ampla faixa de $\mathrm{pH}$ e a água é um fator determinante para o crescimento dos microrganismos.

\section{CONSIDERAÇÕES FINAIS}

A presença das BAL nos queijos Minas artesanais é muito importante não só no processo de fermentação e transformação do leite no queijo, mas também é essencial para o desenvolvimento das características organolépticas do produto, como o aroma, textura e sabor.

Além disso, a atuação das BAL como bioconservantes tem sido amplamente estudada e comprovada através de pesquisas, demonstrando a produção de substâncias 
antimicrobianas e sua ação antagonista sobre patógenos, que possam estar presentes em queijos artesanais, durante o processo de maturação, melhorando a qualidade microbiológica e a segurança alimentar do produto.

Diante dos estudos abordados neste trabalho é possível concluir que, para maior segurança microbiológica, no que se refere ao consumo dos queijos Minas artesanais, é importante ressaltar que um período mínimo de maturação deve ser respeitado, a fim de garantir a ausência ou redução de patógenos causadores de doenças e intoxicações, sendo necessária a avaliação das condições higiênico-sanitárias em que esse queijo foi fabricado e estocado, desde a obtenção da matéria prima até o produto final

\section{REFERÊNCIAS BIBLIOGRÁFICAS}

ALEMDAR, S.; AGAOGLU, S. Survival of Salmonella typhimurium during the ripening of herby cheese (Otlu Peynir). Journal of Food Safety, v. 30, n. 3, p. 526-536, 2010. DOI: 10.1111/j.1745-4565.2010.00263.x

ALEXANDRE, D. P. et al. Atividade antimicrobiana de bactérias lácticas isoladas de queijo-de-Minas artesanal do Serro (MG) frente a microrganismos indicadores. Arquivos Brasileiros de Medicina Veterinária e Zootecnia, v. 54, n. 4, p. 424-428, 2002. DOI: 10.1590/S0102-09352002000400014

AMORIM, A. L. B. C. Avaliação da qualidade higiênica e sanitária de queijos tipo Minas Padrão de fabricação industrial, artesanal e informal. Orientador: Márcia de Aguiar Ferreira. 2013. 53 f. Monografia (Curso de Medicina Veterinária) - Faculdade de Agronomia e Medicina Veterinária, Universidade de Brasília, Brasília, 2013.

ANDRADE, C. R. Diagnóstico da qualidade microbiológica de queijo Serra da Canastra e caracterização de bactérias do gênero Enterococcus. Orientador: Arnaldo Yoshiteru
Kuayne. 2009. 112 f. Dissertação (Mestrado em Tecnologia de Alimentos) - Faculdade de Engenharia de Alimentos, Universidade Estadual de Campinas, Campinas, 2009.

ANDRADE, C. R. G. et al. Propriedades probióticas in vitro de Lactobacillus spp. isolados de queijos Minas artesanais da Serra da Canastra - MG. Arquivos Brasileiros de Medicina Veterinária e Zootecnia, v. 66, n. 5 , p. $1592-1600,2014$. DOI: $10.1590 / 1678-6781$

ANDRETTA, M. et al. Microbial safety status of Serro artisanal cheese produced in Brazil. Journal of Dairy Science, v. 102, n. 12, p. 10790 10798, 2019. DOI: 10.3168/jds.2019-16967

ARMACHUK, M. A. et al. Modificações microbiológicas e físico-químicas durante a maturação de queijo Colonial artesanal produzido com leite cru. Higiene Alimentar, v. 33, n. 288/289, p. 1938-1942, 2019.

BALCIUNAS, E. M. et al. Novel biotechnological applications of bacteriocins: A review. Food Control, v. 32, n. 1, p. 134-142, 2013. DOI: 10.1016/j.foodcont.2012.11.025

BORDIGNON-JUNIOR, S. M. et al. Inibição do crescimento de bactérias Gram-negativas em microdiluição por tratamento com nisina e EDTA. Journal of Biotechnology and Biodiversity, v. 3, n .4, p. 127-135, 2012. DOI: 10.20873/jbb.uft.cemaf.v3n4.bordignon

BORELLI, B. M. et al. Qualidade microbiológica do queijo Minas artesanal maturado, produzido na região da Serra da Canastra - MG. Higiene Alimentar, v. 24, n. 188/189, p. 79-84, 2010.

BORELLI, B. M. et al. Identification of Staphylococcus spp. isolated during the ripening process of a traditional Minas cheese. Arquivo Brasileiro de Medicina Veterinária e Zootecnia, v. 63, n. 2, p. 481-487, 2011. DOI: 10.1590/S0102-09352011000200028

BRASIL. Lei $\mathrm{n}^{\circ} 13.680$, de 14 de junho de 
2018. Altera a Lei $n^{0} 1.283$, de 18 de dezembro de 1950, para dispor sobre o processo de fiscalização de produtos alimentícios de origem animal produzidos de forma artesanal. Diário Oficial da União: seção 1, Brasília, DF, n. 114, p. 02,15 jun. 2018

BRASIL. Ministério da Agricultura e do Abastecimento. Resolução $\mathrm{n}^{\circ} 7$, de 28 de novembro de 2000. Oficializa os critérios de funcionamento e de controle da produção de queijarias, para seu relacionamento junto ao Serviço de Inspeção Federal. Diário Oficial da República Federativa do Brasil: seção 1, Brasília, DF, n. 1, p. 22, 2 jan. 2001.

BRASIL. Ministério da Agricultura, Pecuária e Abastecimento. Instrução Normativa $\mathrm{n}^{\circ} 30$, de 7 de agosto de 2013. Estabelece critérios adicionais para elaboração de Queijos Artesanais. Diário Oficial da República Federativa do Brasil: seção 1, Brasília, DF, n. 152, p. 19, 8 nov. 2013.

BRASIL. Ministério da Agricultura, Pecuária e Abastecimento. Instrução Normativa $n^{0} 57$, de 15 de dezembro de 2011. Permite que os queijos artesanais tradicionalmente elaborados a partir de leite cru sejam maturados por um período inferior a 60 (sessenta) dias e estabelece critérios. Diário Oficial da União: seção 1, Brasília, DF, n. 241, p. 23, 16 dez 2011.

BRASIL. Ministério da Cultura. Instituto do Patrimônio Histórico e Artístico Nacional. Titulação. Confere o Título de Patrimônio Cultural do Brasil ao Modo Artesanal de Fazer Queijo de Minas, nas regiões do Serro, da Serra da Canastra e Salitre/Alto Paranaíba. 2008. Disponível em: http://portal.iphan.gov.br/ uploads/ckfinder/arquivos/Modo_fazer_queijo_ minas_titulacao.pdf.

BRASIL. Ministério da Saúde. Agência Nacional de Vigilância Sanitária. Resolução RDC n 12 , de 2 de janeiro de 2001. Aprova o Regulamento Técnico sobre Padrões Microbiológicos para Alimentos. Diário Oficial da União: seção 1, Brasília, DF, n. 7, p. 45, 10 jan. 2001.
BRUMANO, E C.C. Impacto do tipo de fermento endógeno na qualidade e tempo de maturação de queijo Minas artesanal produzido em propriedades cadastradas pelo IMA (Instituto Mineiro de Agropecuária) na região do Serro-MG. Orientador: Célia Lúcia de Luces Fortes Ferreira. 2016. 158 f. Tese (Doutorado em Ciência e Tecnologia de Alimentos) - Departamento de Tecnologia de Alimentos, Universidade Federal de Viçosa, Viçosa, 2016.

BRUNO, L. M.; CARVALHO, J. D. G. Documentos 124: Microbiota lática de queijos artesanais. Fortaleza: Embrapa Agroindústria Tropical, 2009. 30 p.

CÂMARA, S. P. A. Estudo do potencial bioactivo e tecnológico de bactérias do ácido láctico isoladas de queijo do Pico artesanal. Orientador: Maria de Lurdes Enes Dapkevicius. 2012. 94 f. Dissertação (Mestrado em Tecnologia e Segurança Alimentar) - Departamento de Ciências Agrárias, Universidade dos Açores, Angra do Heroísmo, 2012.

CAMPAGNOLlO, F. B. et al. Selection of indigenous lactic acid bacteria presenting anti-listerial activity, and their role in reducing the maturation period and assuring the safety of traditional Brazilian cheeses. Food Microbiology, v.73, p. 288-297, 2018. DOI: 10.1016/j.fm.2018.02.006

CARDOSO, V. M. et al. The influence of ripening period length and season on the microbiological parameters of a traditional Brazilian cheese. Brazilian Journal of Microbiology, v. 44, n. 3 , p. $743-749$, 2013. DOI: $10.1590 / \mathrm{S} 1517-$ 83822013005000059

CARVALHO, M. M. A agroindústria familiar rural e a produção de queijos artesanais no município de Seara, estado de Santa Catarina - Um estudo de caso. Orientador: Luciana Oliveira de Fariña. 2015. 53 f. Dissertação (Mestrado em Desenvolvimento Rural Sustentável) - Centro de Ciências Agrárias, 
Universidade Estadual do Oeste do Paraná, Marechal Cândido Rondon, 2015.

CEZAR, R. D. S. et al. Detection of Mycobacterium bovis in artisanal cheese in the state of Pernambuco, Brazil. International Journal of Mycobacteriology, v. 5, n. 3, p. 269272, 2016. DOI: 10.1016/j.ijmyco.2016.04.007

CHESCA, A. C.; GONÇALVES, Y. C.; SANTOS, A. L. S. Patógenos em queijo Minas frescal e curado. Higiene Alimentar, v. 29, n. 242/243, p. 90-93, 2015.

CHIODA, T. P. et al. Inibição do crescimento de Listeria monocytogenes em queijo Minas Frescal elaborado com cultura de Lactobacillus acidophilus. Revista Portuguesa de Ciências Veterinárias, v. 101, n. 557-558, p. 121-124, 2006.

COSTA, A C. C. C. Isolamento de bactérias láticas produtoras de bacteriocinas e avaliação de sua atividade frente a patógenos alimentares em sistema de bioconservação de produto lácteo. Orientador: Flávio Alves da Silva. 2016. 58 f. Dissertação (Mestrado em Ciência e Tecnologia de Alimentos) - Escola de Agronomia e Engenharia de Alimentos, Universidade Federal de Goiás, Goiânia, 2016.

COSTA, H. H. S et al. Potencial probiótico in vitro de bactérias ácido-láticas isoladas de queijode-Minas artesanal da Serra da Canastra, MG. Arquivo Brasileiro de Medicina Veterinária e Zootecnia, v. 65, n. 6, p. 1858-1866, 2013. DOI: 10.1590/S0102-09352013000600038

CRUZ, F. T; SCHNEIDER, S. Qualidade dos alimentos, escalas de produção e valorização de produtos tradicionais. Revista Brasileira de Agroecologia, v. 5, n. 2, p. 22-38, 2010.

CUNHA, A. L. F. S. Potencial probiótico in vitro de Lactobacillus spp. isolados de queijo Minas artesanal da Serra do Salitre - MG. Orientador: Marcelo Resende de Souza. 2018. 48 f. Dissertação (Mestrado em Produção Animal)
- Instituto de Ciências Agrárias, Universidade Federal de Minas Gerais, Montes Claros, 2018.

DIAS, G. M. P. Potencial tecnológico de bactérias ácido láticas isoladas de queijo de Coalho artesanal produzido no Município de Venturosa - Pernambuco. Orientador: Ana Lúcia Figueiredo Porto. 2014. 114 f. Tese (Doutorado em Ciências Biológicas) - Universidade Federal de Pernambuco, Recife, 2014.

DINIZ, M. F. S. Queijo Canastra: Um estudo envolvendo aspectos culturais e parâmetros de inocuidade do alimento. Orientador: Gilma Lucazechi Sturion. 2013. 160 f. Dissertação (Mestrado em Ciência e Tecnologia de Alimentos) - Escola Superior de Agricultura Luiz de Queiroz, Universidade de São Paulo, Piracicaba, 2013.

DORES, M. T.; FERREIRA, C. L. L. F. Queijo Minas artesanal, tradição centenária: Ameaças e desafios. Revista Brasileira de Agropecuária Sustentável, v. 2, n. 2, p. 26-34, 2012. DOI: 10.21206/rbas.v2i2.163

DORES, M. T. et al. Enterotoxigenic potential of Staphylococcus aureus isolated from Artisan Minas cheese from the Serra da Canastra-MG, Brazil. Food Science and Technology, v. 33, n. 2, p. $271-275,2013$. DOI: $10.1590 / \mathrm{S} 0101-$ 20612013005000033

ECKERT, R. G.; WEBBER, M. Controle de qualidade microbiológico de queijos maturados comercializados na feira do pequeno produtor da cidade de Cascavel-PR. Higiene Alimentar, v. 30, n. 252/253, p. 80-85, 2016.

EMATER - Empresa de Assistência Técnica e Extensão Rural de Minas Gerais. Queijo Minas Artesanal: Mapa do Queijo. Disponível em: http://www.emater.mg.gov. br/portal.do?flagweb=site_pgn_downloads vert $\&$ grupo $=135 \&$ menu $=59$. Acesso em: 23 maio 2019.

FERNANDES, R. V. B. et al. Avaliação físico- 
química, microbiológica e microscópica do queijo artesanal comercializado em Rio Paranaíba-MG. Revista do Instituto de Laticínios Cândido Tostes, v. 66, n. 382, p. 21-26, 2011.

FERREIRA, J. S. et al. Conhecimento, atitudes e práticas em segurança alimentar de manipuladores de alimentos em hospitais públicos de Salvador, Bahia. Revista Baiana de Saúde Pública, v. 37, p. 35-55, 2013. Supl. 1.

FERREIRA, R. M. et al. Quantificação de coliformes totais e termotolerantes em queijo Minas Frescal artesanal. PUBVET Publicações em Medicina Veterinária e Zootecnia, v. 5, n. 5, ed. 152, art. 1022, 2011.

GERIA, M. et al. Antagonistic activity of dairy lactobacilli against gram-foodborne pathogens. Acta Scientiarum, v. 36, n. 1, p. 1-6, 2014. DOI: 10.4025/actascitechnol.v36i1.18776

GIAZZI, A. Caracterização e estudo do perfil tecnológico de bactérias ácido láticas isoladas de queijos tipo Minas artesanais e leite cru. Orientador: Marly Sayuri Katsuda. 2017. 75 f. Dissertação (Mestrado em Tecnologia de Alimentos) - Universidade Tecnológica Federal do Paraná, Londrina, 2017.

GUEDES NETO, L. G. Isolamento, identificação e avaliação de características probióticas de bactérias ácido-láticas isoladas de amostras de queijo de Coalho produzidas em Pernambuco - Brasil. Orientador: Wagner Luiz Moreira dos Santos. 2008. 190 f. Tese (Doutorado em Ciência Animal) - Universidade Federal de Minas Gerais, Belo Horizonte, 2008.

GUEDES NETO, L. G. et al. Atividade antimicrobiana de bactérias ácido-lácticas isoladas de queijos de coalho artesanal e industrial frente a microrganismos indicadores. Arquivos Brasileiros de Medicina Veterinária e Zootecnia, v. 57, supl. 2, p. 245-250, 2005.

HEREDIA-CASTRO, P. Y. et al. Bacteriocinas de bactérias ácido lácticas: Mecanismos de acción y actividad antimicrobiana contra patógenos em quesos. Interciencia: Revista de Ciencia y Tecnología de América, v. 42, n. 6, p. 340-346, 2017.

JERONYMO, A. B. O. Avaliação do potencial probiótico de bactérias ácido láticas produtoras de substância antimicrobiana isoladas de mussarela de búfala. Orientador: Ana Lúcia Barretto Penna. 2013. 108 f. Dissertação (Mestrado em Microbiologia) Universidade Estadual Paulista, São José do Rio Preto, 2013.

LIMA, B. B.; LEAL, M. C. Parâmetros indicadores de qualidade de queijos artesanais comercializados em Castro-PR. Orientador: José Mauro Giroto. 2017. 30 f. Trabalho de Conclusão de Curso (Tecnólogo de Alimentos) - Universidade Tecnológica Federal do Paraná, Ponta Grossa, 2017.

LIMA, C. D. L. C. et al. Bactérias do ácido láctico e leveduras associadas com o queijo-deMinas artesanal produzido na região da Serra do Salitre, Minas Gerais. Arquivo Brasileiro de Medicina Veterinária e Zootecnia, v. 61, n. 1 , p. $266-272$, 2009. DOI: $10.1590 / \mathrm{S} 0102-$ 09352009000100037.

LIMA, C. D. L. C; CERQUEIRA, M. M. O. P.; ROSA, C. A. Boas práticas de fabricação e a qualidade do queijo Minas artesanal da Serra do Salitre. Higiene Alimentar, v. 25, n. 2, p. 159-161, 2011.

LUIZ, L. M. P. et al. Isolation and identification of lactic acid bacteria from Brazilian Minas artisanal cheese. CyTA - Journal of Food, 2016. DOI: $10.1080 / 19476337.2016 .1219392$

MACHADO, J. R. et al. Avaliação microbiológica das mãos e fossas nasais de manipuladores de alimentos da unidade de alimentação e nutrição de um hospital universitário. Revista Medicina (Ribeirão Preto), v. 42, n. 4, p. 461-465, 2009. DOI: $10.11606 /$ issn.2176-7262.v42i4p461-465 
MALAGUETA-JÚNIOR, F. G.; SILVA, M. E. T.; SOUZA, G. C. S. Avaliação higiênico-sanitário das mãos de manipuladores, equipamentos e utensílios no mercado da carne de Limoeiro do Norte-CE. In: CONGRESSO NORTENORDESTE DE PESQUISA E INOVAÇÃO, 7., 2012, Palmas. Anais [...]. Palmas: Instituto Federal de Educação, Ciência e Tecnologia do Tocantins, 2012.

MARTINS, J. M. et al. Determining the minimum ripening time of artisanal Minas cheese, a traditional Brazilian cheese. Brazilian Journal of Microbiology, v. 46, n. 1, p.219-230, 2015. DOI: $10.1590 / \mathrm{S} 1517-838246120131003$

MATA, G. M. S. C. et al. Performance of two alternative methods for Listeria detection throughout Serro Minas cheese ripening. Brazilian Journal of Microbiology, v. 47, n. 3, p. 749-756, 2016. DOI: 10.1016/j. bjm.2016.04.006

MELlO, A. G. et al. Conhecimento dos manipuladores de alimentos sobre boas práticas nos restaurantes públicos populares do Estado do Rio de Janeiro. Brazilian Journal of Food Technology, v. 13, n. 1, p. 60-68, 2010. DOI: 10.4260/BJFT2010130100008

MELO, F. D. et al. Avaliação da inocuidade e qualidade microbiológica do queijo artesanal serrano e sua relação com as variáveis físicoquímicas e o período de maturação. Acta Scientiae Veterinariae, v. 41, n. 1, p. 1-7, 2013.

MILANI, E. et al. Microbiological, biochemical and rheological changes throughout ripening of kurdish cheese. Journal of Food Safety, v. 34, n. 2 , p.168-175, 2014. DOI: $10.1111 /$ jfs. 12110

MINAS GERAIS. Decreto $\mathrm{n}^{\circ} 44.864$, de 01 de agosto de 2008. Altera o Regulamento da Lei $\mathrm{n}^{\circ} 14.185$, de 31 de janeiro de 2002, que dispõe sobre o processo de produção de Queijo Minas Artesanal. Diário do Executivo. Belo Horizonte, MG, p. 01, 02 ago 2008.
MINAS GERAIS. Lei $\mathrm{n}^{\circ} 20.549$, de 18 de dezembro de 2012. Dispõe sobre a produção e a comercialização dos queijos artesanais de Minas Gerais. Diário do Executivo do Estado de Minas Gerais: caderno 1, Belo Horizonte, MG, n. 236, p. 1, 19 dez. 2012.

MINAS GERAIS. Lei Estadual n ${ }^{\circ} 23.157$, de 18 de dezembro de 2018. Dispõe sobre a produção e a comercialização dos queijos artesanais de Minas Gerais. Minas Gerais Diário do Executivo: col 1, Belo Horizonte, MG, p. 01, $19 \operatorname{dez} 2018$.

MINAS GERAIS. Secretaria de Estado de Agricultura, Pecuária e Abastecimento. Instituto Mineiro de Agropecuária. Portaria no 1305, de 30 de abril de 2013. Estabelece diretrizes para a produção do queijo Minas artesanal. Belo Horizonte, 2013.

MIYASHIRO, S. et al. Detection of Brucella abortus DNA in illegal cheese from São Paulo and Minas Gerais and differentiation of B19 vaccinal strain by means of the Polymerase Chain Reaction (PCR). Brazilian Journal of Microbiology, v.38, n. 1, p.17-22, 2007. DOI: $10.1590 / \mathrm{S} 1517-83822007000100005$

MORICONI, P. R. et al. Mycobacteria in Minas cheese commercialized in open fairs in São Paulo, Brazil. Brazilian Journal of Veterinary Research and Animal Science, v. 55, n. 4, e146525, 2018. DOI: 10.11606/issn.1678-4456. bjvras.2018.146525

NISHIE, M.; NAGAO, J.; SONOMOTO, K. Antibacterial peptides "bacteriocins": An overview of their diverse characteristics and applications. Biocontrol Science, v. 17, n. 1, p. 1-16, 2012. DOI: $10.4265 /$ bio. 17.1

OLIVEIRA, D. L. S. Staphylococcus spp. isolados de queijo artesanal da Serra da Canastra: Identificação bioquímica e molecular, detecção de genes para produção de toxinas, susceptibilidade a antimicrobianos e atividade 
antagonista in vitro frente a Lactobacillus spp. Orientadora: Mônica Maria Oliveira Pinho Cerqueira. 2012. 47 f. Dissertação (Mestrado em Ciência Animal) - Universidade Federal de Minas Gerais, Belo Horizonte, 2012.

O L I V E IRA, L. G. Caracterização microbiológica e físico-química durante a maturação em diferentes épocas do ano de queijo Minas artesanal de produtores cadastrados da mesorregião de Campo das Vertentes - MG. Orientador: Marcelo Resende de Souza. 2014. 111 f. Dissertação (Mestrado em Ciência Animal) - Universidade Federal de Minas Gerais, Belo Horizonte, 2014.

PAGTHINATHAN, M.; NAFEES, M. S. M. Biochemistry of cheese ripening. AGRIEAST Journal of Agricultural Sciences, v. 10, p. 16-26, 2015. DOI: 10.4038/agrieast.v10i0.25

PEHRSON, M. E. S. F. Efeito da adição de culturas probióticas sobre aspectos microbiológicos e parâmetros fermentativos de Queijo Artesanal das Terras Altas da Mantiqueira. Orientador: Ismael Maciel de Mancilha. 2017. 128 f. Tese (Doutorado em Ciências) - Universidade de São Paulo, Lorena, 2017.

PEREIRA, M. L.; RODRIGUES, P. R.; FORTES-DIAS, C. L. Listeria monocytogenes: prevalência em queijo tipo Minas e recuperação nos produtos artificialmente contaminados e mantidos a $-18^{\circ} \mathrm{C}$ por 20 meses. Higiene Alimentar, v. 23, n. 176/177, p. 102-109, 2009.

PINTO, M. S. et al. Segurança alimentar do queijo Minas artesanal do Serro, Minas Gerais, em função da adoção de boas práticas de fabricação. Pesquisa Agropecuária Tropical, v. 39, n. 4, p. 342-347, 2009a.

PINTO. M. S. et al. Survival of Listeria innocua in Minas Traditional Serro cheese during ripening. Food Control, v. 20, p. 1167-1170, 2009b. DOI: 10.1016/j.foodcont.2009.02.007
PINTO, M. S et al. Características físicoquímicas e microbiológicas do queijo artesanal produzido na microrregião de Montes Claros - MG. Revista do Instituto de Laticínios Cândido Tostes, v. 71, n. 1, p. 43-52, 2016. DOI: 10.14295/2238-6416.v70i1.514

RAFAEL, V. C. Fenótipos da microbiota predominante do fermento endógeno (pingo) relevantes para as características e segurança microbiológica do queijo Minas Artesanal da Serra da Canastra. Orientador: Célia Lúcia de Luces Fortes Ferreira. 2017. 158 f. Tese (Doutorado em Ciência e Tecnologia de Alimentos) - Universidade Federal de Viçosa, Viçosa, 2017.

RESENDE, E. C. Aspectos sensoriais e microbiológicos do queijo Minas artesanal da microrregião Campo das Vertentes. Orientador: Fernando Antônio Resplande Magalhães. 2014. 114 f. Dissertação (Mestrado em Ciência e Tecnologia do leite) - Universidade Federal de Juiz de Fora, Juiz de Fora, 2014.

RESENDE, M. F. S. et al. Queijo de Minas artesanal da Serra da Canastra: Influência da altitude das queijarias nas populações de bactérias acidolácticas. Arquivo Brasileiro de Medicina Veterinária e Zootecnia, v. 63, n. 6 , p. $1567-1573,2011$. DOI: $10.1590 / \mathrm{S} 0102-$ 09352011000600039

REZENDE, P. H. L. et al. Aspectos sanitários do queijo Minas artesanal comercializado em feiras livres. Revista do Instituto de Laticínios Cândido Tostes, v. 65, n. 377, p. 36-42, 2010.

ROLA, J.; KORPYSA-DZIRBA, W.; OSEK, J. Prevalence of Staphylococcus aureus and staphylococcal enterotoxins at different stages of production of raw milk cheeses - Preliminary results. Bulletin of the Veterinary Institute in Pulawy, v. 57, p. 341-345, 2013. DOI: 10.2478/ bvip-2013-0059

SANTIAGO-RODRÍGUEZ, M. R. et al. Survival of Brucella abortus aqp X mutant 
in fresh and ripened cheeses. Foodborne pathogens and disease, v. 12, n. 2, 2015. DOI: $10.1089 /$ fpd.2014.1823

SEIXAS, F. N. Identificação filogenética e caracterização tecnológica da microbiota ácido lática autóctone do queijo artesanal serrano catarinense e seu potencial antagonista a patógenos. Orientador: Valerni Beloti. 2014. 139 f. Tese (Doutorado em Ciência Animal) - Universidade Estadual de Londrina, Londrina, 2014.

SILVA, C. C. G.; SILVA, S. P. M.; RIBEIRO, S. C. Application of bacteriocins and protective cultures in dairy food preservation. Frontiers in Microbiology, v. 9, art. 594, 2018a. DOI: 10.3389/fmicb.2018.00594

SILVA, L. M. Perfil microbiológico de queijo Minas frescal industrializado e artesanal comercializado em Goiânia, Goiás. Orientador: Maria Raquel Hidalgo Campos. 2015. 82 f. Dissertação (Mestrado em Nutrição e Saúde) Universidade Federal de Goiás, Goiânia, 2015.

SILVA, M. R. et al. Ocorrência de Brucella em queijo Minas artesanal da microrregião do Serro: Um importante problema de saúde pública. Revista Médica de Minas Gerais, v. 28, supl. 5, p. 79-84, 2018b.

SILVA, N. C.; TUNES, R. M. M.; CUNHA, M. F. Avaliação química de queijos Minas artesanais frescos e curados em Uberaba, MG. PUBVET Publicações em Medicina Veterinária e Zootecnia, v. 6, n. 16, ed. 203, art. 1358, 2012.

SOARES, D. B. et al. Análise sanitária e físico-química e adequação bacteriológica do queijo Minas artesanal produzido em duas propriedades. Ciência Animal Brasileira, v. 19, e36499, p. 1-13, 2018. DOI: 10.1590/18096891v19e-36499

SOBRAL, D. et al. Principais defeitos em queijo Minas artesanal: Uma revisão. Revista do Instituto de Laticínios Cândido Tostes, v. 72 , n. 2 , p. $108-120,2017$. DOI: $10.14295 / 2238$ 6416.v72i2.600

STARIKOFF, K. R. et al. Decline in Mycobacterium bovis and Brucella abortus populations during the maturation of experimentally contaminated parmesantype cheese. Semina: Ciências Agrárias, v. 37 , n. 5, supl. 2, p. 37-43, 2016. DOI: 10.5433/1679-0359.2016v37n5Supl2p3743

TEODORO, V. A. M. et al. Segurança e Boas Práticas de Fabricação de queijos artesanais mineiros. EPAMIG Informe Agropecuário, v. 34 , n. 273 , p. $30-43,2013 a$.

TEODORO, V. A. M. et al. Importância de implementação de boas práticas na produção de leite para a fabricação de queijos artesanais de Minas Gerais. EPAMIG Informe Agropecuário, v. 34 , n. 273 , p.17-29, 2013 b.

VASEK, O. M; MAZZA, S. M.; GIORI, G. S. Physicochemical and microbiological evaluation of Corrientes artisanal cheese during ripening. Food Science and Technology, v. 33, n. 1 , p. 151-160, 2013. DOI: 10.1590/S010120612013005000021

ZUIN, L. F. S.; ZUIN, P. B. Produção de alimentos tradicionais: Contribuindo para o desenvolvimento local/regional e dos pequenos produtores rurais. Revista Brasileira de Gestão e Desenvolvimento Regional, v. 4, n. 1, p. 109-127, 2008. 